\title{
Rancang Bangun Inverter Tiga Phasa Back to Back Converter Pada Sistem Konversi Energi Angin
}

\author{
Rifdian I.S \\ Program Studi Diploma III Teknik Listrik Bandar Udara \\ Akademi Teknik dan Keselamatan Penerbangan Surabaya \\ J1 Jemur Andayani I/73 Wonocolo Surabaya 60236 \\ Telp.(031)841087, Fax. (031)8490005 \\ Email : rifdian.anto@gmail.com
}

\begin{abstract}
Sistem konversi energi angin terdiri dari turbin angin, generator, dan konverter. Konverter dalam energi angin tersusun dari back to back converter yang terdiri dari rectifier dan inverter. Kecepatan angin yang berubah-ubah akan mengakibatkan naik turunnya tegangan output generator dan frekuensi output generator. Pengaturan tegangan ouput dilakukan dengan pengaturan eksitasi pada generator. Untuk menghilangkan efek naik turunnya frekuensi digunakan rectifier dan inverter yang tersusun dalam back to back converter. Pada penelitian ini akan disusun rancang bangun dari rectifier dan inverter dari back to back converter yang digunakan.

Back to back converter ini terdiri dari rangkaian penyearah tidak terkontrol, buck converter, dan Inverter 3 fasa yang digunakan untuk menggerakkan motor induksi 3 fasa. Modul ini mendapat sumber dari jala-jala 3 fasa yang dihubungkan pada rangkaian penyearah yang diatur melalui variac 3 fasa dengan keluaran 0 - 200 Vdc. Kemudian keluaran DC dari rangkaian penyearah terhubung dengan buck converter, sehingga keluaran DC tersebut dapat memenuhi input tegangan pada inverter 3 fasa yaitu 0 - 100 Vac. Dengan keluaran tegangan inverter untuk menjalankan motor induksi 3 fasa. Teknik switching yang digunakan untuk penyulutan mosfet pada inverter adalah PWM (Pulse Width Modulated) dengan mode switching tegangan konduksi $180^{\circ}$, dimana Pembangkitan sinyal PWM ini dikontrol melalui mikrokontroler ATmega 8535. Dari hasil pengujian didapatkan $\%$ error tegangan keluaran pada inverter 3 fasa sebesar 26,47\% untuk duty cycle $50 \%$ dan 11,11\% untuk duty cyle $70 \%$.
\end{abstract}

KEYWORD : Sistem konversi, rectifier dan inverter, converter

\section{PENDAHULUAN}

Proses alih teknologi yang cepat saat ini cukup memberikan kemudahan dalam melakukan berbagai hal aktifitas manusia. Hal ini dikarenakan salah satu pelaku utamanya adalah mahasiswa yang didasari dari tujuan pendidikan yang tinggi yaitu untuk menumbuhkan, mengembangkan dan menguasai iptek. Dalam rangka meningkatkan kemampuan, Untuk itu sebagai kelengkapan modul praktikum pada laboratorium listrik, maka dirancanglah suatu modul inverter 3 fasa sebagai suplai listrik untuk mengembangkan proses konversi energi angin.

Modul ini terdiri dari rangkaian penyearah tidak terkontrol, buck converter, dan Inverter 3 fasa yang digunakan untuk suplai listrik. Modul ini mendapat sumber dari jala-jala 3 fasa yangdihubungkan pada rangkaian penyearah yang diatur melalui variac 3 fasa dengan keluaran $0-200$ Vdc. Kemudian keluaran DC dari rangkaian penyearah terhubung dengan buck converter, sehingga keluaran DC tersebut dapat memenuhi input tegangan pada inverter 3 fasa yaitu $0-100$ Vac. Dengan keluaran tegangan inverter untuk suplai listrik. Teknik switching yang digunakan untuk penyulutan IGBT pada inverter adalah PWM (Pulse Width Modulated) dengan mode switching tegangan konduksi $180^{\circ}$, dimana Pembangkitan sinyal PWM ini dikontrol melalui mikrokontroler ATmega 8535. Dengan dikembangkannya modul praktikum elektrik ini, diharapkan dapat memperlancar jalannya praktikum sekaligus menambah kekurangan modul praktikum yang telah ada, dan proses pembelajaran di bidang konversi energi angin menjadi energi listrik menjadi lebih baik. 


\section{TUJUAN}

Merencanakan dan membuat inverter tiga phasa sebagai pendukung back to back converter pada sistem konversi energi angin. Dengan suplai dari rangkaian penyearah 3 fasa dan dihubungkan dengan buck converter dengan penyulutan IGBT pada inverter menggunakan SPWM.

\section{BATASAN MASALAH}

Pada penelitian ini membahas mengenai perencanaan dan pembuatan rangkaian suplai motor induksi tiga fasa yaitu:

- Rangkaian Buck Converter.

Rangkaian ini dirancang untuk menurunkan tegangan dari rangkaian penyearah tiga fasa menjadi tegangan 0- $100 \mathrm{Vdc}$.

- Perencanaan rangkaian PWM

Rangkaian ini sebagai pembangkit gelombang pulsa secara analog.

- Rangkaian Inverter 3 fasa

Rangkaian ini dirancang untuk mengkonversi tegangan keluaran 0 - 100Vdc dari buck converter menjadi tegangan keluaran 0 - 100 Vac per fasa dari inverter 3 fasa.

- Data Motor Induksi 3 fasa sebagai beban uji sebagai berikut :

Daya $=0,5 \mathrm{Kw}$, Tegangan nominal $\mathrm{Y} / \Delta=380 / 220 \mathrm{~V}$, Frekuensi $=50 \mathrm{~Hz}$, kecepatan $=1380 \mathrm{rpm}$

\section{KONFIGURASI SISTEM}

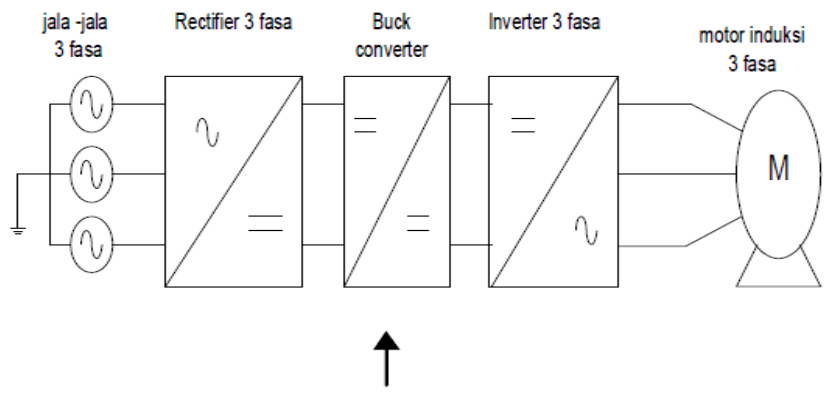

PWM Analog

Gambar 1. Blok diagram sistem perencanaan dan pembuatan modul inverter 3 phasa

Keterangan gambar :

a. Sumber tegangan adalah berasal dari jala-jala PLN 3 fasa 380 Vac yang selanjutnya akan diubah menjadi tegangan DC melalui rectifier.

b. Buck converter berfungsi sebagai penurun tegangan DC dari tegangan keluaran rectifier menjadi masukan pada inverter 3 fasa yang diatur duty cycle-nya.

c. Kemudian masukan inverter dari keluaran rangkaian buck converter tegangan DC diubah menjadi tegangan 0 - 100Vac. Dimana teknik switching yang digunakan untuk penyulutan 
Mosfet adalah PWM dengan mode konduksi $180^{\circ}$, yang pembangkitannya akan dilakukan melalui mikrokontroler untuk penyulutan. Kemudian digunakan untuk menggerakkan motor induksi 3 fasa sebagai beban uji.

\section{PRINSIP KERJA SISTEM}

Inverter 3 fasa ini mendapat suplai dari jala - jala 3 fasa yang kemudian dihubungkan dengan variac yang diatur hingga keluaran mencapai masukan dari PWM Analog buck converter yang sebelumnya diatur duty cycle-nya 0,7 sehingga dapat diturunkan sesuai masukan dari inverter. Penyulutan inverter ini melalui mikrokontroler ATMega8535 yang diatur frekwensi switchingnya sehingga keluaran dapat menggerakkan motor induksi 3 fasa.

\section{PERENCANAAN PERANGKAT LUNAK}

Dari hasil perancangan perangkat lunak, dibuatlah program yang telah dirancang mengguanakan Code Vision AVR. Code Vision AVR Merupakan suatu software yang digunakan dalam penulisan program yang nantinya akan di download pada microcontroller AVR ATmega 8535. Dalam penggunaan microcontroller AVR menggunakan software CodeVision AVR. Seperti umumnya microcontroller, program untuk microcontroller AVR ditulis menggunakan bahasa assembly. CodeVision AVR merupakan software $\mathrm{C}$-cross compiler, dimana program dapat ditulis menggunakan bahasa-C. dengan menggunakan pemrograman bahasa-C diharapkan waktu desain (developing time) akan menjadi lebih singkat. Setelah program dalam bahasa-C ditulis dan dilakukan kompilasi tidak terdapat kesalahan (error) maka proses download dapat dilakukan.

Sistem kerja perangkat lunak pada perancangan ini secara umum dapat dijelaskan pada gambar flowchart. Kehandalan dari sistem sangat bergantung dari ketelitian dari sensor, dan ketepatan dari ADC (analog to digital converter) yang digunakan. Flowchart tersebut juga menjelaskan bagaimana proses pensaklaran/penyulutan pada mosfet inverter.

Ketepatan waktu pada pensaklaran/penyulutan sangat menentukan dalam kualitas tegangan ouput tiga fasa yang digunakan. Frekuensi tegangan output inverter juga sangat ditentukan pada waktu pensaklaran/penyulutan tersebut. 


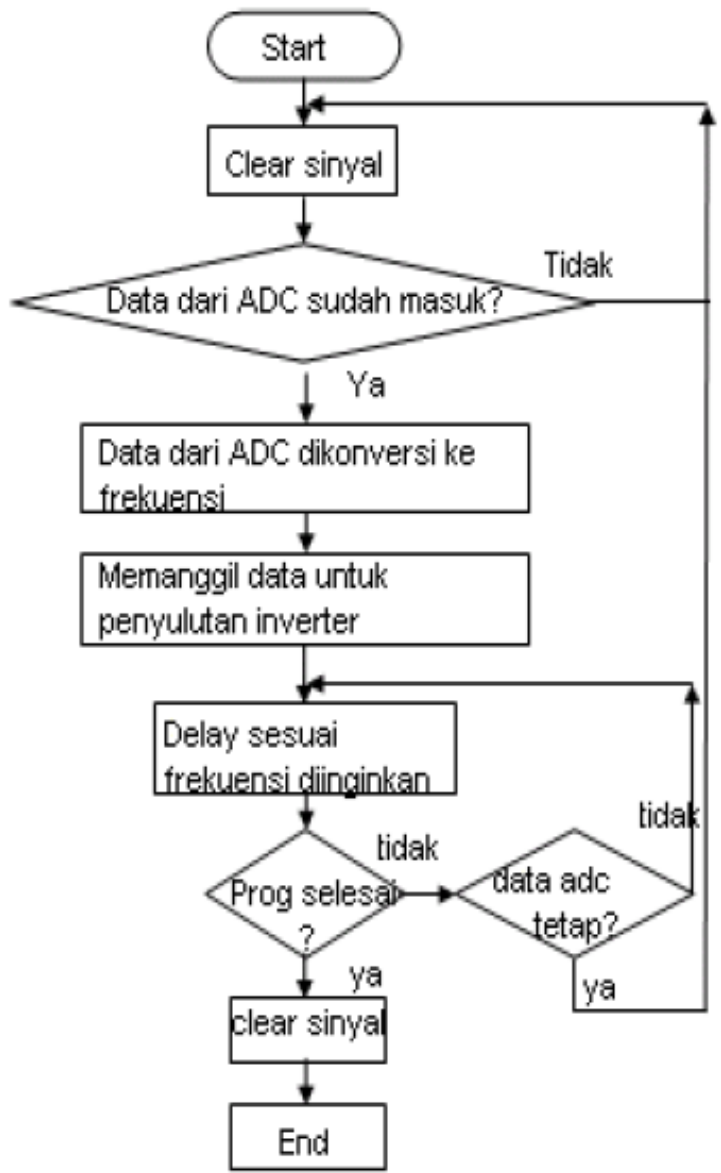

Gambar 2. Flowchart penyulutan inverter

\section{HASIL PENGUJIAN SISTEM}

\section{Pengujian Mikrokontroller}

Untuk pengujian mikrokontroler yang berkaitan dengan software maka kami membutuhkan supply de minimum system, dan seperangkat kabel. Dalam pengambilan data saya melakukan percobaan atau mengambil data pwm yang dikeluarkan oleh minimum system. Seperti terlihat pada gambar dibawah ini:

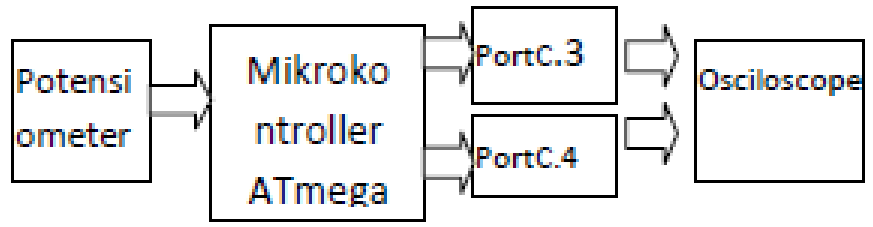

Gambar 3. Blok diagram pengujian mikrokontroler Atmega 8535

Pada gambar 4 terlihat ada dua gelombang yang aktif dan offnya berbeda sesuai dengan apa yang diprogramkan. Gelombang tersebut dihasilkan dari program pwm. Yaitu antara U, V, W berbedak waktu aktifnya. Itu dikarenakan Menggunakan metode pemrograman 1800, yang digunakan untuk penyulutan mosfet secara bergantian. 


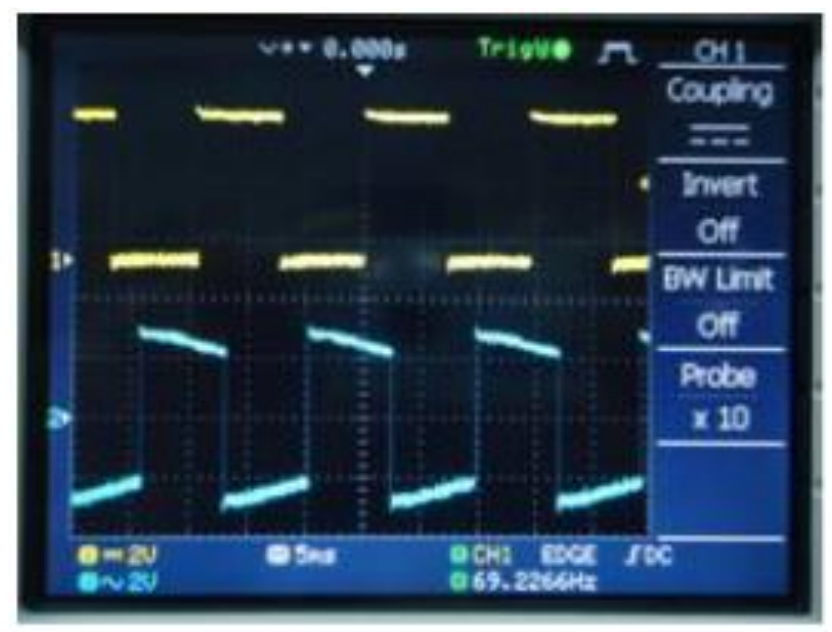

Gambar 4. Gelombang keuaran sinyal U dan V dari mikrokontroler

\section{Pengujian Buck Converter}

Pengujian Buck converter dilakukan untuk mengetahui perubahan penyulutan dari mosfet dari keluaran pensaklaran serta untuk mengetahui keluaran rangkaian buck converter memperoleh tegangan masukan sebesar $100 \mathrm{Vdc}$, dan di sisi keluaran diberi beban berupa lampu $100 \mathrm{~W}$.Pada saat tidak ada switching maka besar tegangan keluaran sama dengan tegangan masukan. Apabila mosfet pada buck converter diberi frekuensi switching sebesar $40 \mathrm{kHz}$ dengan duty cycle 0,7 . maka tegangan keluaran akan turun menjadi sebesar $79 \mathrm{Vdc}$.

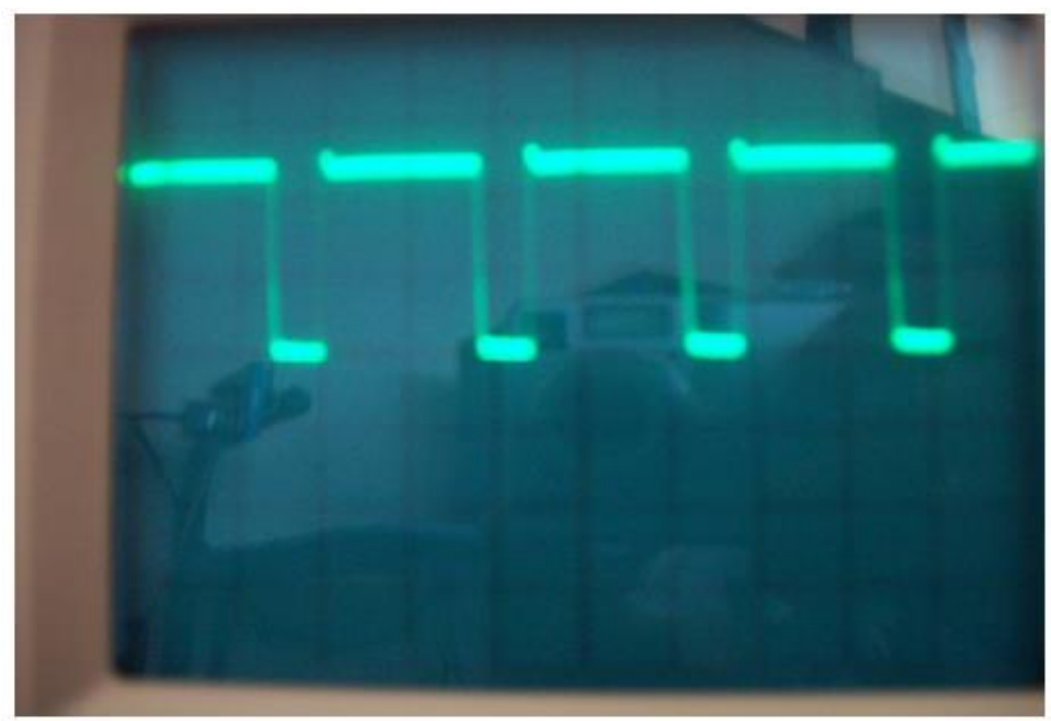

Gambar 5. Tampilan osciloscope sinyal pensaklaran pada mosfet Tabel 1. Hasil pengujian rangkaian buck converter 


\begin{tabular}{|c|c|c|c|c|}
\hline Frekwensi & $\begin{array}{c}\text { Duty } \\
\text { cycle } \\
\text { (Teori) }\end{array}$ & $\begin{array}{c}\text { Vin } \\
\text { (volt) }\end{array}$ & $\begin{array}{c}\text { Vout } \\
\text { (volt) }\end{array}$ & lout \\
\hline $40 \mathrm{Khz}$ & 0,7 & $10 \mathrm{v}$ & $7 \mathrm{v}$ & $0,1 \mathrm{~A}$ \\
\hline $40 \mathrm{Khz}$ & 0,7 & $20 \mathrm{v}$ & $15 \mathrm{v}$ & $0,1 \mathrm{~A}$ \\
\hline $40 \mathrm{Khz}$ & 0,7 & $30 \mathrm{v}$ & $22 \mathrm{v}$ & $0,1 \mathrm{~A}$ \\
\hline $40 \mathrm{Khz}$ & 0,7 & $40 \mathrm{v}$ & $31 \mathrm{v}$ & $0,2 \mathrm{~A}$ \\
\hline $40 \mathrm{Khz}$ & 0,7 & $50 \mathrm{v}$ & $38 \mathrm{v}$ & $0,25 \mathrm{~A}$ \\
\hline $40 \mathrm{Khz}$ & 0,7 & $60 \mathrm{v}$ & $46 \mathrm{v}$ & $0,25 \mathrm{~A}$ \\
\hline $40 \mathrm{Khz}$ & 0,7 & $70 \mathrm{v}$ & $54 \mathrm{v}$ & $0,3 \mathrm{~A}$ \\
\hline $40 \mathrm{Khz}$ & 0,7 & $80 \mathrm{v}$ & $63 \mathrm{v}$ & $0,3 \mathrm{~A}$ \\
\hline $40 \mathrm{Khz}$ & 0,7 & $90 \mathrm{v}$ & $71 \mathrm{v}$ & $0,3 \mathrm{~A}$ \\
\hline $40 \mathrm{Khz}$ & 0,7 & $100 \mathrm{v}$ & $79 \mathrm{v}$ & $0,3 \mathrm{~A}$ \\
\hline
\end{tabular}

\section{Pengujian rangkaian inverter}

Inverter diberi beban motor induksi 3 fasa dengan sumber dari buck converter menghasilkan tegangan input $70 \mathrm{Vdc}$ dan tegangan keluaran 51 Vac. Tegangan output inverter turun sebesar $20 \%$ untuk duty cycle pada buck converter maksimum.

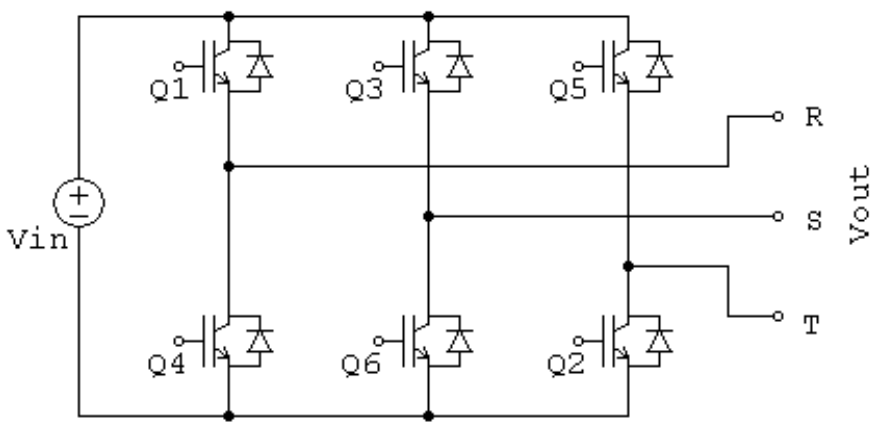

Gambar 6. Skema rangkaian inverter 3 fasa

Untuk penyulutan inverter ini ada tiga masukan penyulutan yaitu Qa, Qb dan Qc ketika Qa on maka Q1 akan on dan Q4 akan off, ketika Qb on maka Q3 akan on dan Q6 off dan ketika Qc on maka Q5 on dan Q2 off, dari karakteristik tersebut maka untuk mendrive inverter ini dibutuhkan rangkaian logika not untuk mendrive Q2, Q6 dan Q2 sehingga blok diagram dengan sistem keseluruhan adalah :

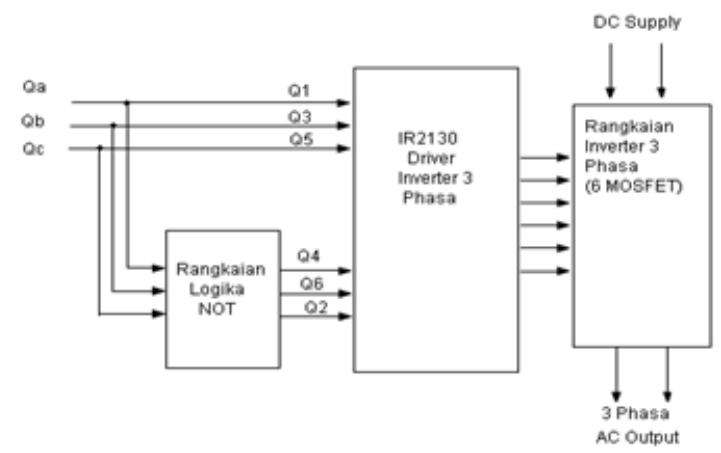

Gambar 7. Blok rangkaian inverter 3 fasa 


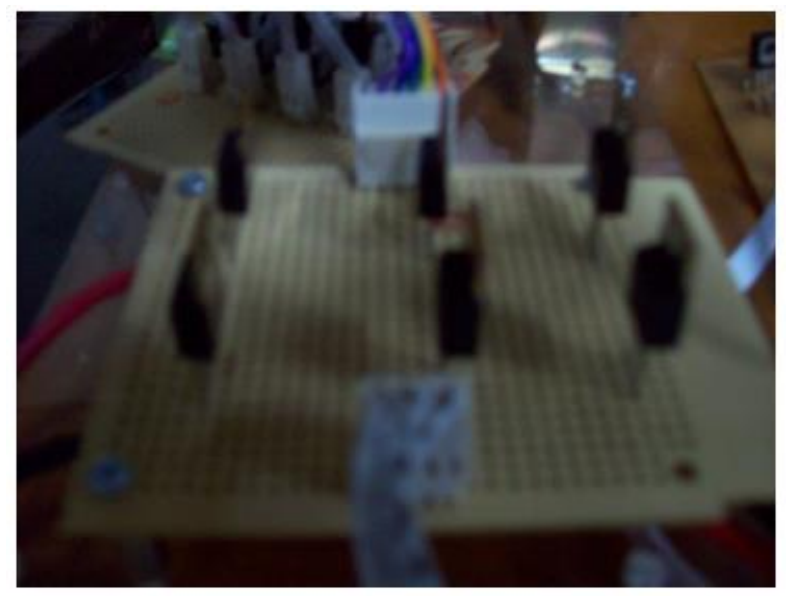

Gambar 5. Susunan komponen rangkaian inverter 3 fasa

Berdasarkan hasil pengujian rangkaian inverter, diperoleh output tegangan dari rangkaian inverter adalah seperti tabel 2 .

Tabel 2. Hasil pengukuran tegangan output inverter 3 fasa

\begin{tabular}{|c|c|}
\hline Vdc (input) & Vac (output) \\
\hline 12 volt & 8 volt \\
\hline 22 volt & 16 volt \\
\hline 30 volt & 23 volt \\
\hline 40 volt & 30 volt \\
\hline 50 volt & 37 volt \\
\hline 60 volt & 44 volt \\
\hline 70 volt & 51 volt \\
\hline
\end{tabular}

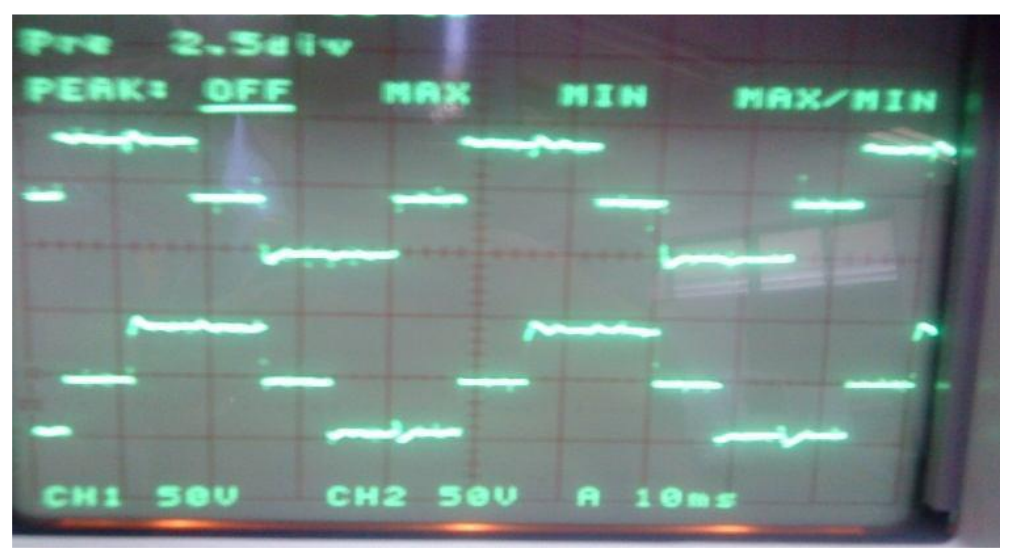

Gambar 6. Bentuk tegangan ouput inverter pada osciloscope 


\section{Pengujian Integrasi Modul}

Untuk pengujian hasil integrasi diperoleh dengan memberikan beban dan diambil data hasil pengukuran. Hasil pengukuran dengan beban motor induksi 3 fasa dengan daya $=0,75 \mathrm{Kw}$, $\mathrm{f}=50 \mathrm{~Hz}$ dan duty cycle buck converter yang diatur $50 \%$ dan $70 \%$.

Tabel 3. Pengukuran pada buck converter dalam integrasi modul

\begin{tabular}{|c|c|c|c|c|}
\hline $\begin{array}{c}\text { Frekwe } \\
\text { nsi }\end{array}$ & $\begin{array}{c}\text { Duty } \\
\text { Cycle( } \\
\text { Teori) }\end{array}$ & Vin & Vout & $\begin{array}{c}\text { Duty } \\
\text { Cycle( } \\
\text { Praktek } \\
\text { ) }\end{array}$ \\
\hline $40 \mathrm{Khz}$ & 0.5 & $64 \mathrm{v}$ & $34 \mathrm{v}$ & 0.53 \\
\hline $40 \mathrm{Khz}$ & 0.7 & $60 \mathrm{v}$ & $45 \mathrm{v}$ & 0.75 \\
\hline
\end{tabular}

Tabel 4. Hasil pengujian inverter 3 fasa dalam integrasi modul

\begin{tabular}{|c|c|c|c|c|c|}
\hline $\begin{array}{l}\text { Duty } \\
\text { Cycle }\end{array}$ & Vin & $\begin{array}{l}\text { Vout } \\
\text { A-B }\end{array}$ & $\begin{array}{l}\text { Vout } \\
\text { A-C }\end{array}$ & $\begin{array}{l}\text { Vout } \\
\text { B-C }\end{array}$ & $\begin{array}{l}\text { Vout A- } \\
\text { Netral }\end{array}$ \\
\hline 0.5 & $34 \mathrm{v}$ & $25 \mathrm{v}$ & $25 \mathrm{v}$ & $25 \mathrm{v}$ & $17 \mathrm{v}$ \\
\hline 0.7 & $45 \mathrm{v}$ & $40 \mathrm{v}$ & $40 \mathrm{v}$ & $40 \mathrm{v}$ & $25 \mathrm{v}$ \\
\hline
\end{tabular}

Perhitungan \% error :

Duty cycle $=0.5$

Vdc input $=34$ Volt

Voutput fasa-fasa $=25$ Volt

Voutput fasa - netral(teori) $=19.63$ Volt

Voutput fasa - netral $($ praktek $)=17$ Volt

Maka $\%$ error fasa-fasa $=\frac{34-25}{25} \times 100 \%=26,47 \%$

Maka \% error fasa-netral $=\frac{19,63-17}{19,63} \times 100 \%=13.39 \%$

Duty cycle $=0.7$

$\mathrm{Vdc}$ input $=45$ volt

Voutput fasa-fasa $=40$ Volt

Voutput fasa - netral $($ teori $)=25.98$

Voutput fasa - netral $($ praktek $)=25$

Maka \% error $=\frac{45-40}{45} \times 100 \%=11.11 \%$

Maka \%error $=\frac{25,98-25}{25,98} \times 100 \%=3.7 \%$ 


\section{KESIMPULAN}

Setelah melalui tahap perencanaan dan pembuatan modul inverter 3 phase sebagai suplai listrik pada sistem konversi energi angin, ada beberapa hal yang dapat disimpulkan yaitu:

1. Dengan beban lampu 100 watt tegangan keluaran pada buck converter sesuai dengan perhitungan yang diharapkan, jika penyulutan mosfet dengan PWM menggunakan duty cycle $70 \%$ sehingga \% kesalahan rata-rata sebesar $10 \%$

2. Semakin kecil duty cycle yang diatur pada buck converter maka penurunan tegangan keluaran inverter 3 fasa semakin besar yaitu 10 volt jika menggunakan duty cycle $50 \%$ dan 5 volt jika menggunakan duty cycle $70 \%$

3. Teknik switching penyulutan pada mosfet sangat mempengaruhi bentuk gelombang dan tegangan keluaran rangkaian Inverter 3 fasa

4. Inverter bekerja pada frekuensi antara $5 \mathrm{~Hz}$ sampai $50 \mathrm{~Hz}$ dengan step $5 \mathrm{~Hz}$.

5. Inverter bekerja maksimal dengan beban motor induksi arus yang dikeluarkan sebasar $2 \mathrm{~A}$ pada frekuensi $5 \mathrm{~Hz}$.

6. Inverter dapat digunakan untuk pengaturan motor induksi dari kecepatan 150 RPM pada frekuensi $5 \mathrm{~Hz}$ sampai sekitar $1100 \mathrm{RPM}$ pada frekuensi $50 \mathrm{~Hz}$.

7. Tegangan output dari inverter sebesar 218 volt AC pada frekuensi $50 \mathrm{~Hz}$. Untuk mendapatkan tegangan output maksimal sampai 220 Volt AC 3 fasa pada inverter bisa didapat dari pemilihan komponen switching yang tepat, dalam hal ini adalah tipe MOSFET.

\section{DAFTAR PUSTAKA}

[1] Yudi Amrillah, "Sepeda Elektrik Menggunakan Penggerak Motor Induksi Tiga Fasa (Buck-Boost Konverter Inverter Tiga Fasa)", Proyek Akhi PENS -ITS 2008.

[2] Afif Salakhudin, "Rancang Bangun Inverter Satu Fase pada Daya Cadangan Rumah Tangga (switching PWM)", Proyek Akhir PENS-ITS 2007.

[3] Muhammad H.Rasyid "Elektronika Daya". Edisi bahasa Indonesia jilid I. PT.Prenhallindo, Jakarta,1993.

[4] Datasheet RF Modules, diakses 29 Januari 2009, oleh MaxStream.inc.

[5] Zuhal "Dasar Tenaga Listrik" ITB BANDUNG 2000.

[6] Kristianto H “Inverter Treprogram Berbasis Atmega 8535sebagai sumber listrik untuk penerangan” Proyek akhir PENS ITS 2010.

[7] Andrianto heri "Pemrograman Mikrokontroller AVRATMEGA16" Informatika, 2008.

[8] Winoto ardi "Mikrokontroller AVR Atmega 8/32/16/8535" informatika, 2008.

[9] Dimas Pungky,"Rancang Bangun Inverter Satu Fase pada Daya Rumah Tangga(switching PWM)",Proyek Akhir PENS-ITS 2010.

[10] Muhammad H.Rashid,"Power Electronics Circuits,Devices, and Application 3", Prentice Hall 2004.

[11] Hasna Abadiningrum, "Sepeda Elektrik Menggunakan Penggerak Motor Induksi Tiga

Fasa (Mikrokontroller sebagai Driver pada Buck-Boost Konverter Inverter Tiga Fasa)", Proyek Akhir PENS -ITS 2008.

[12] A.M. Gole, Sinusoidal Pulse width modulation, Power Electronics, Internet, 2000

[13] Datasheet AVR ISP Programmer, diakses 1 Februari 2011, http://www.avrispprogrammer.com/literature

[10] Pengertian dan manfaat mosfet, diakses 3 februari 2011, http://id.wikipedia.org/wiki/MOSFET

[11] Datasheet ATMega8535 8-bit Microcontroller with 16K Bytes In- System Programmable Flash diakses 1 Februari 2011,dari alldatasheet. http://www.alldatasheet.com/datasheetpdf/pdf/78532/ATMEL/ATMEGA8535.html 